\title{
CONTEXTO DOS IMIGRANTES NA PANDEMIA E SUAS IMPLICAÇÕES PARA A PESSOA IDOSA: BRASIL E MÉXICO
}

\author{
Luciana Mitsue Sakano Niwa' \\ ORCID: 0000-0002-9342-7454
}

Erika Adriana Torres Hernández"

ORCID: 0000-0001-9273-1035

Denise Philomene Joseph Van Aanholt'II ORCID: 0000-0003-1439-0321

Bárbara Bartuciotti Giusti"'

ORCID: 0000-0002-2716-801X

Suely Itsuko Ciosak ${ }^{11}$ ORCID: 0000-0001-5884-2524

'DCEG-SP.

São Paulo, São Paulo, Brasil.

"Universidad Autónoma de San Luis Potosí. Facultad de Enfermería y Nutrición. San Luis Potosí, San Luis Potosí, México.

"'Universidade de São Paulo. São Paulo, São Paulo, Brasil.

Autor Correspondente: Luciana Mitsue Sakano Niwa E-mail: lucianamsn@usp.br
Como citar:

Niwa LMS, Hernández EAT, Van Aanholt DPH, Giusti BB, Ciosak SI. Contexto dos imigrantes na pandemia e suas implicações para a pessoa idosa: Brasil e México. In: Santana RF (Org.). Enfermagem gerontológica no cuidado do idoso em tempos da COVID 19. Brasilia, DF: Editora ABen; 2021. 171 p. (Serie Enfermagem e Pandemias, 5). https://doi.org/10.51234/aben.21.e05.c13

\section{INTRODUÇÃO}

Os fenômenos migratórios são deslocamentos populacionais relacionados com as dinâmicas demográficas do local e são motivados por fatores de atração e repulsão. Ao longo da história, vários movimentos migratórios foram e são importantes. Os fluxos migratórios podem ser classificados como internacionais, quando os indivíduos migram de um país para o outro e migrações internas quando o indivíduo se desloca dentro do mesmo país mudando de estado ou região ${ }^{(1-3)}$.

Os movimentos migratórios transformam sociedades, pois com a saída ou a chegada de pessoas, pode ocorrer miscigenação da população, hibridização cultural, mas, também, a desestabilização econômica e de oferta de trabalho. Além disso, os fenômenos migratórios podem estar relacionados a preconceitos étnicos, religiosos e culturais; conflitos de cunho político, econômico e social, fuga por escassez alimentar ou desastres naturais como tsunamis e terremotos ${ }^{(1-3)}$.

Além das crises, os fenômenos migratórios também, podem ser relacionados a busca de melhores acessos, empregos, desenvolvimento social, segurança contra conflitos internos, guerras civis e governos ditatoriais e qualidade de vida $^{(1-2)}$. As oportunidades de uma vida melhor têm atraído pessoas para países emergentes como o Brasil, conhecido por ser um país de acolhimento e oportunidades.

Dados do Ministério da Justiça ${ }^{(4)}$ apontam que de 2011 a 2018 foram registrados no Brasil cerca de 774,2 mil imigrantes. O Comitê Nacional para refugiados mencionou o Brasil como nação acolhedora por possuir cerca de 43 mil refugiados, em 2020, destes 38 mil são jovens venezuelanos com boa escolaridade que atravessam a fronteira em busca de melhores condições de vida ${ }^{(5)}$. As três principais nacionalidades que compõem o grupo de imigrantes são os haitianos, venezuelanos e colombianos ${ }^{(4)}$.

No entanto, estima-se que aproximadamente 3 milhões 
de brasileiros residem no exterior. Os principais destinos dos brasileiros até o final de 2016 foram: Estados Unidos da América (1.410.000), Paraguai (332.042), Japão (170.229), Reino Unido (120.000) e Portugal (116.271) (6). Brasil e México compõem um binômio imigratório importante onde o número de imigrantes mexicanos para o Brasil aumentou 160\% de 2005 a 2015. Há de se considerar que os dados dos refugiados são de difícil acesso, compondo um grande desafio no concepto epidemiológico e de necessidades dessa população (4). No México estima-se que cerca de 12 milhões de mexicanos residem no exterior, a grande maioria (97\%) nos Estados Unidos ${ }^{(7)}$.

De uma população de quase 57 milhões de latinos nos Estados Unidos, mais de 63\% são de origem mexicana, ou seja, mais de 36 milhões de pessoas. As causas da migração são diferentes de acordo com o gênero: nove em cada 10 mulheres migram para juntar-se a suas famílias, trabalhar ou estudar. Em contraste, oito em cada 10 homens o fazem para encontrar trabalho ou conseguir um emprego melhor remunerado ${ }^{(7)}$.

Os mexicanos são o maior grupo de estrangeiros nos Estados Unidos. Eles representam 25\% dos 44,5 milhões de imigrantes em 2017, de acordo com estimativas de um grupo de reflexão sobre questões de imigração baseado em Washington. Em 2014, a população imigrante do México diminuiu após décadas de crescimento sustentado. Em 2007, atingiu um pico de 12,8 milhões e, em 2014, foi de 11,7 milhões ${ }^{(7)}$.

Vivemos ainda um momento ímpar por causa da pandemia da Covid-19. O vírus foi detectado em Wuhan, província de Hubei, China, em dezembro de 2019 envolvendo comerciantes de um mercado de animais vivos e se espalhou rapidamente pelo mundo. A Organização Mundial da Saúde ${ }^{(8)}$ decretou pandemia da Covid-19 em 11 de março de 2020 pela velocidade de propagação da doença e Wuhan se tornou o epicentro da pandemia.

A pandemia da Covid-19, além de dizimar milhares de vítimas, isolar e distanciar pessoas do convívio social, também paralisou a mobilidade humana e os fluxos migratórios. $O$ aumento exponencial de casos e a alta velocidade de propagação internacional, fez com que vários países fechassem suas de fronteiras (impedindo a entrada de não nacionais temporariamente), como estratégia de contenção da disseminação do vírus. Entretanto, o fechamento das fronteiras não tem impedido o deslocamento de pessoas, especialmente aquelas em extrema vulnerabilidade.

O aumento do fluxo clandestino migratório durante uma pandemia é preocupante. O fechamento de fronteiras sem política e protocolos que favoreçam uma migração segura, organizada e regular dos imigrantes em situação de vulnerabilidade pode facilitar a disseminação do vírus e colocar não só essas pessoas em risco, como também a população do país de destino, especialmente os idosos que são considerados grupo de risco e principais vítimas da Covid-19.

Levando em conta a necessidade emergencial de ampliar e atualizar com rapidez o conhecimento científico em descobrir os impactos da Covid-19, emergiu a necessidade de refletir sobre o contexto dos imigrantes, sua relação com a pessoa idosa no atual cenário da pandemia da Covid-19 no Brasil e no México.

\section{OBJETIVO}

Refletir o impacto da relação entre imigração e o atual cenário pandêmico da Covid-19 em especial a pessoa idosa.

\section{MÉTODOS}

Estudo teórico-reflexivo baseado em literatura nacional e internacional e nos relatos de experiência das autoras. $\mathrm{O}$ texto discorre sobre a experiência dos fluxos migratórios do Brasil e do México considerando os imigrantes, migrações internas e emigração e suas relações com a formação de vínculos, rede de apoio, desafios, oportunidades e repercussões para os idosos diante do cenário de pandemia da COVID-19. 


\section{RESULTADOS}

\section{Contexto da migração no Brasil}

\section{Fechamento das fronteiras e situações dos imigrantes}

O primeiro caso da Covid-19 na América do Sul, foi no Brasil em 26 de fevereiro e em 3 de março já havia dois casos confirmados de indivíduos que haviam retornado de viagem à Itália e 488 suspeitos $^{(9)}$.

O receio de "importar" mais casos da Covid-19 gerou medo e preconceito em relação aos asiáticos e aos que voltavam de viagens internacionais para o Brasil. Medidas progressivas de fechamento das fronteiras brasileiras proibindo, com poucas exceções, o ingresso de não nacionais foram adotadas.

Primeiramente houve a restrição da entrada no País, por via terrestre de não nacionais provenientes do Uruguai, por 30 dias, segundo a Portaria Conjunta Interministerial n.132. Em seguida, muitas outras portarias foram criadas no mês de março com duração de 30 dias com o objetivo de impedir a entrada de estrangeiros no país, ora por transportes aquaviários, ora em determinada fronteira do país. As exceções à restrição de entrada foram relacionadas à situação familiar (cônjuge, companheiro (a), filho (a), pai ou curador brasileiro), a função (a serviço de missão estrangeira ou organismo internacional) ou a residência no Brasil, bem como a autorização governamental relacionada ao interesse público ${ }^{(10)}$.

É válido ressaltar que muitas dessas portarias ferem a convenção dos direitos humanos. Contudo, o fundamento constitucional para a restrição da mobilidade internacional humana era a proteção à vida e à saúde, pelo contágio do vírus que tinha atingido cerca de 180 países em julho de $2020^{(10)}$.

Apesar do fechamento das fronteiras, muitos casos de imigrações clandestinas de refugiados de países vizinhos foram reportados. Esses fluxos migratórios inseguros colocam em risco tanto os imigrantes como a população brasileira, elevando a probabilidade de contágio da COVID-19 e piorando ainda mais a situação dos indivíduos vulneráveis.

Tanto os imigrantes como os refugiados compartilham com os brasileiros a dura realidade econômica face à pandemia, pois muitos estão inseridos no mercado de trabalho informal, sem proteção social e foram afetados pelo fechamento de seus trabalhos. Além disso, muitos estão em situação de vulnerabilidade vivendo de forma precária nas cidades brasileiras e com dificuldade em pleitear o auxílio emergencial concedido pelo governo federal.

Contudo ações de solidariedade e amparo junto às comunidades imigrantes têm acontecido por todo país. Muitas dessas ações são lideradas por pessoas idosas, que investiram seu tempo e expertise na confecção de máscaras, arrecadação de cestas básicas e kit de higiene e limpeza para distribuir (por outras pessoas) a esses refugiados. Os sentimentos de ajudar o próximo e sentir-se útil, contribuem para que o enfrentamento do distanciamento imposto pela pandemia seja percebido de maneira mais leve, pelos idosos.

Imigrantes podem vivenciar muitas perdas durante a experiência migratória, como familiares e entes queridos, a língua, cultura, posição social, contato étnico e religioso e a própria integridade física. O período de adaptação e acolhimento pelo país de destino pode ser adverso e causar problemas de saúde como depressão, ansiedade, estresse e outros distúrbios mentais.

É válido ressaltar que o Sistema Único de Saúde (SUS) faz toda a diferença no atual contexto, pois atende aos brasileiros, imigrantes e refugiados, visto que na Constituição Federal de 1988, está posto que a "saúde é direito de todos e dever do Estado" e é nessa afirmação que a saúde pública e gratuita possibilita à toda população, sem discriminação, acesso ao atendimento de saúde e as unidades de saúde, já estava sobrecarregado antes da pandemia, quanto mais agora atendendo os casos da Covid-19. Infelizmente imigrantes e refugiados, mundo afora, não dispõem de atendimento à saúde e ficam desamparados quando mais precisam, o momento de adaptação ao novo país e nem todos conhecem esse direito. 
Por outro lado, idosos com 60 e mais anos, inseridos no mercado de trabalho podem se sentir ameaçados pelo aumento de mão-de-obra jovem e barata dos imigrantes. Os idosos são considerados como o principal grupo de risco da Covid-19 pelas alterações fisiológicas do envelhecimento e pela presença de doenças crônicas, e tem engrossado as taxas de mortalidade e, como "medida de proteção", alguns empregadores decidiram demitir este grupo etário, o que configura um ato de ageísmo ou idadismo, além de comprometer a renda familiar, haja vista que muitos idosos são arrimos de família.

Acreditamos que no Brasil há espaço e oportunidades a todos. Seja nos acolhimentos aos imigrantes e refugiados e no cuidado e a participação da pessoa idosa no protagonismo de ações sociais, econômicas e de trabalho, porem é necessário que haja envolvimento de órgãos governamentais ou não, para orientação, coordenação, encaminhamentos e monitoramento das atividades e ocorrências.

\section{Migração interna}

Quanto à migração interna, logo após o primeiro caso da Covid-19 no Brasil, muitos idosos migraram para casa de familiares no interior e no litoral para se protegerem da pandemia que crescia exponencialmente nos grandes centros urbanos.

Em São Paulo, a migração precoce visava manter a qualidade de vida na companhia dos familiares (filhos, netos) e com uma estrutura de residência (casa) melhor que os apartamentos pequenos com pouca iluminação natural onde residiam nos grandes centros urbanos. Com o passar do tempo muitas famílias migraram para o interior e o litoral em busca de acolhimento em casa de parentes (a maioria idosos) em busca de espaços maiores, pela saudade dos parentes (pais e avós) e até mesmo pela crise econômica por não conseguirem manter o custo de vida ou pela falta de previsão para voltar ao antigo normal.

O processo de migração interna nem sempre foi uma decisão da pessoa idosa. Muitas vezes era imposto pela família com o objetivo de protegê-los da Covid-19, pois as taxas de mortalidade na população idosa só aumentavam no transcorrer dos dias. Para alguns idosos, a obrigação de sair de seu lar mesmo com a justificativa de preservar a vida, foi revoltante, pois sua autonomia foi negligenciada. As medidas de distanciamento rapidamente se transformaram em aprisionamento causando isolamento, depressão e conflitos familiares.

Por outro lado, quando a decisão de passar o período pandêmico fora do lar, foi compartilhada em conjunto com a pessoa idosa, houve melhor aceitação e compreensão das medidas de distanciamento e harmonia nas relações familiares, apesar de não existir lugar melhor que a própria casa.

Infelizmente, alguma dessas migrações transferiu a doença às cidades menores sem estruturas de saúde robustas para enfrentar a Covid-19. Pessoas assintomáticas que contaminaram parentes idosos, que tiveram a manifestação grave e evoluíram para óbito, principalmente àqueles que se mudou para a residência do idoso trouxe sofrimento mental e a sensação de culpa por ter levado a Covid-19, provocando abalos a inúmeras famílias.

Não é nossa intenção cercear o direito de ir e vir das pessoas, mas alertá-las sobre a importância da prática das medidas sanitárias, higiênicas e de distanciamento que, apesar de simples, são desprezadas. Ao migrar para outras localidades é extremamente importante seguir rigorosamente essas medidas.

\section{Diáspora brasileira}

A diáspora brasileira é impulsionada por problemas econômicos, sociais e divergências políticas provocadas pela crise econômica de 2014. Os principais destinos dos brasileiros são os países desenvolvidos como Estados Unidos, Japão e países europeus como Portugal e Reino Unido.

Os emigrantes geralmente têm de 30 a 49 anos, com família constituída, alta qualificação, perfil empreendedor e saem do país de origem em busca de segurança e estabilidade ${ }^{(11)}$. Geralmente não precisam sustentar os que permaneceram no Brasil. Contudo, a preocupação é bilateral, pois é difícil lidar com a distância física e medidas distintas de contenção do vírus entre os países. 
Outro movimento migratório que tem sido observado no Brasil é o de idosos aposentados para Portugal em busca de desfrutar de sua aposentadoria com segurança, qualidade de vida e estabilidade econômica. Estes idosos se beneficiam do acordo de dupla tributação entre Portugal e Brasil e ao mesmo tempo do regime de isenção de impostos sobre a aposentadoria em Portugal, fato que atraem estes idosos a viverem a velhice em Portugal ${ }^{(12)}$.

Diante da pandemia da Covid-19, pelo fechamento das fronteiras em vários países e por ser o principal grupo de risco da doença, idosos que buscavam morar em outros países seja por sonho, ou por retorno a pátria de seus ancestrais, terão que esperar o controle efetivo da disseminação do vírus ou a vacina para darem continuidade a seus planos.

\section{Contexto da migração no México}

\section{A perspectiva do México}

Geograficamente, o México tem apenas duas fronteiras, cada uma com suas próprias particularidades em termos de migração: como país de trânsito e de origem. A fronteira sul do México é com a Guatemala, que serve como um ponto de entrada para os centro-americanos que procuram atravessar o México para os Estados Unidos, utilizando o México como um país de trânsito durante a migração. Ao norte do México, a fronteira é com os Estados Unidos, um país de destino de uma grande população mexicana, que tradicionalmente se caracteriza pela natureza de trabalho intensivo de deslocamento da população masculina rural, nas idades produtivas, com as consequentes repercussões socioeconômicas, políticas e culturais para ambos os países. Esta migração tem sido favorecida pela taxa de crescimento demográfico da população mexicana em idade de trabalhar e pela dinâmica insuficiente da economia nacional para proporcionar um trabalho decente e bem remunerado ${ }^{(13-14)}$.

Atualmente, os mexicanos continuam sendo o principal grupo de imigrantes em 43 estados da União Americana e sua inserção nesse contexto social e político é complicada em comparação com outros migrantes, dado seu status indocumentado e baixos níveis de educação. Campos e Covarrubias ${ }^{(13)}$ argumentam que o que caracteriza a população migrante mexicana é seu perfil predominantemente econômico, com uma concentração etária de jovens e adultos jovens, especialmente homens; deixando nos seus lugares de origem, na sua grande maioria, as mulheres, onde são deixados para cuidar de netos ou pessoas com deficiência ${ }^{(15)}$.

É de conhecimento público que Donald Trump, atual presidente dos Estados Unidos, fez comentários depreciativos em relação ao México, apontando como ação prioritária a deportação de imigrantes em situação irregular, catalogando-os como corruptos, criminosos e violadores, indicando também o seu desejo de construir um muro entre as fronteiras dos Estados Unidos e do próprio México que deve ser pago pelo México.

Esses dois pontos, deportação de imigrantes e construção do muro, não são situações encorajadoras para o México uma vez que afetarão substancialmente os anos de esforço que procuraram melhorar a qualidade de vida das famílias mexicanas que dependem do apoio econômico dos trabalhadores imigrantes nos Estados Unidos; as remessas que são enviadas para território mexicano podem ser afetadas tanto pela deportação de imigrantes como pela retenção de impostos elevados para a construção do muro e o seu impacto refletirá na redução dos investimentos em saúde, habitação, alimentação e educação para eles e as suas famílias. Trump desencadeou todos os alarmes possíveis no México, sendo para a enfermagem uma questão sociopolítica de consideração, uma vez que é uma situação que vai além de uma simples transferência territorial ou construção de muros, mas uma mudança na dinâmica social que tem um impacto na construção da saúde da população ligada às experiências migratórias.

As migrações internacionais no século XXI têm sido cada vez mais intensas entre os países do Sul global, devido às restrições impostas pelos países do Norte para a entrada e permanência de migrantes internacionais e consistem em importante elemento na reconfiguração das migrações e seus destinos no mundo( ${ }^{(16)}$. 
No que diz respeito à migração a partir da América Central, esta se tornou um problema devido à fuga maciça dos locais de origem pela violência, pobreza e exclusão social, bem como pelas políticas de contenção que obrigam os migrantes centro-americanos a atravessar o México, expondo-os aos riscos de trânsito não documentado através deste país.

Embora o fenômeno da migração traga benefícios e desenvolvimento a ambos os países de origem, trânsito e destino, influenciando positivamente os seus aspectos econômicos, sociais e culturais, as condições de vida e o contexto em que as populações migrantes vivem nem sempre são visíveis.

A esse respeito, é de notar que embora a migração em si não implique necessariamente um risco para a saúde, as condições em torno do processo migratório podem expor os migrantes a maiores riscos de saúde, aumentando assim a sua vulnerabilidade biológica, social, psicológica, econômica e cultural. A xenofobia e a discriminação, a falta de informação relevante e contextualizada, as políticas limitadas a cada país e as violações dos direitos laborais são algumas das ameaças à saúde enfrentadas por estas populações, com as implicações para a saúde física e psicológica do processo de migração em trânsito(17).

\section{Implicações da migração e da Covid 19 nas pessoas idosas}

Em meados de março de 2020, as fronteiras norte e sul do México com os Estados Unidos e a Guatemala, respectivamente, decidiram fechar suas fronteiras terrestres a viagens não essenciais. O executivo federal mexicano pediu às pessoas que estavam em outros países, especialmente nos Estados Unidos, que não retornassem ao México, a fim de evitar um aumento do contágio. Essas medidas trouxeram grandes implicações para os idosos que permanecem em contextos migratórios; por um lado, aqueles que tiveram que voltar para casa, ou tiveram que ir para a casa dos pais, colocando em risco a saúde dos idosos que, além de sua idade, tinham condições de saúde subjacentes como doenças cardiovasculares, respiratórias ou degenerativas crônicas.

Por outro lado, para os idosos que permaneceram em seus locais de origem, o cuidado dos netos e da família tornou-se mais complexo; o isolamento social, acompanhado pelo fechamento de escolas e creches, desencadeou o aumento da carga de cuidado dos idosos e colocou-os em uma corda bamba entre estar isolados em suas casas e estar expostos ao contágio para manter a funcionalidade e o cuidado da família do migrante.

No entanto, não são apenas as condições de saúde e o envelhecimento que colocam as pessoas idosas em risco. São as respostas dos sistemas de saúde que se torna mecânico e instrumental para piorar a saúde e as condições de vida dessas pessoas idosas que são responsáveis pelo cuidado das famílias migrantes.

Por isso, é importante gerar estratégias de proteção aos idosos que são chefes de família de migrantes e são duplamente vulneráveis: por causa da condição pandêmica e da precariedade em que vivem, sendo esta última o gatilho para a migração de seus parentes.

Sob estas condições, as estratégias prevenção geral e ações específicas para o cuidado das pessoas idosas durante a pandemia Sars-Cov-2, referidas por Huenchuan ${ }^{(18)}$, devem ser aprimoradas para garantir que os idosos recebam apoio de suas comunidades durante esta pandemia, com atenção especial para aqueles idosos que vivem sozinhos ou em comunidades de baixa renda, como é a maioria dos contextos migratórios no México, e que têm acesso desigual aos cuidados de saúde.

\section{CONSIDERAÇÕES FINAIS}

Vivemos um momento singular por causa da pandemia do novo coronavírus Sars-Cov-2 e suscitar a necessidade de atenção integral e em rede de imigrantes, considerando os fluxos migratórios e formação de vínculos no país torna-se de fundamental importância.

Brasil e México, diferente de países de primeiro mundo, tem um grande desafio para combater a Covid-19, por apresentarem níveis de desigualdade social e informalidade. Seguir as orientações de distanciamento 
social pode tornar-se difícil e para muitos impraticáveis. Apesar dos esforços em oferecer benefício emergencial ou auxílio governamental, objetivando que se cumpra o distanciamento social, muitos não conseguiram benefícios e apoios por inúmeras razões, deixando os indivíduos ainda mais vulneráveis.

Esse cenário é ainda mais agravante aos grupos que já eram fragilizados antes da pandemia, como migrantes que se deslocam entre cidades, estados e países, tentando garantir sua subsistência e agora tentando também, evitar o contágio pelo vírus, principalmente os idosos, grupo principal de risco da Covid-19.

As perspectivas brasileira e mexicana mostram o grande desafio do cuidado aos idosos nos contextos migratórios diante desta pandemia; embora cada país tenha suas próprias particularidades, o ponto de convergência é o mesmo para ambas as latitudes: promover o cuidado e segurança dos idosos.

Conhecer as principais redes de apoio social que existem na comunidade para o enfrentamento da vida diária, bem como em situações de crise, divulgar os equipamentos sociais disponíveis para que o idoso possa acessar em situação de necessidade ou dificuldades, poderão ajuda-los no enfrentamento a esta pandemia.

Para esta faixa etária, vale ressaltar que apesar da necessidade de distanciamento, os laços familiares devem ser mantidos e estimulados, para manter as condições emocionais saudáveis.

\section{AGRADECIMENTO}

\section{Agradecimentos a ABEn e DCEG nacional.}

\section{REFERÊNCIAS}

1. Patarra NL. Migrações Internacionais de e para o Brasil contemporâneo: volumes, fluxos, significados e políticas [Internet]. 2005[cited $2020 \mathrm{Jul} 01$ ]. Available from: http://www.scielo.br/pdf/spp/v19n3/v19n3a02.pdf

2. Teixeira PE, Braga AMC, Baeninger R, (Orgs). Migrações: implicações passadas, presentes e futuras [Internet]. 2012[cited 2020 Jul 01]. Available from: https://www.marilia.unesp.br/Home/Publicacoes/migracoes2_ebook.pdf

3. Vesentini JW. Geografia: o mundo em transição. São Paulo: Ática; 2011.

4. Comitê Nacional de Refugiados (CONARE). Nação acolhedora: Brasil tem cerca de 43 mil refugiados [Internet]. 2020 [cited $2020 \mathrm{Jul}$ 01]. Available from: https://www.gov.br/casacivil/pt-br/assuntos/noticias/2020/junho/ nacao-acolhedora-brasil-tem-cerca-de-43-mil-pessoas-reconhecidas-atualmente-como-refugiadas

5. Ministério das Relações Exteriores (BR). Brasileiros no mundo: estimativas populacionais da comunidade [Internet]. 2016[cited $2020 \mathrm{Jul}$ 01]. Available from: http://www.brasileirosnomundo.itamaraty.gov.br/a-comunidade/estimativaspopulacionais-das-comunidades/Estimativas\%20RCN\%202015\%20-\%20Atualizado.pdf

6. Ministério da Justiça e Segurança Pública (BR). Relatório Anual do Observatório das migrações Internacionais [Internet] 2019 [cited 2020 Jul 01]. Available from: https://www.justica.gov.br/news/collective-nitf-content-1566502830.29

7. Consejo Nacional de Poblácion Consejo. Migración y salud. Perfil de los latinoamericanos en Estados Unidos. México. 2015.

8. Organização Mundial de Saúde (OMS). WHO Virtual press conference on COVID-19 [Internet]. 2020[cited 2020 Jul 01]. Available from: https://www.who.int/docs/default-source/coronaviruse/transcripts/who-audio-emergencies-coronaviruspress-conference-full-and-final-11 mar2020.pdf?sfvrsn=cb432bb3_2

9. Croda JHR, Garcia LP. Resposta imediata da Vigilância em Saúde à epidemia da COVID-19. Epidemiol Serv Saúde. 2020;29(1):e2020002. http://dx.doi.org/10.5123/s1679-49742020000100021

10. Ramos AC. Construindo Muralhas: o fechamento de fronteiras na pandemia da Covid-19. In: Migrações Internacionais e a Pandemia da Covid-19 [Internet]. Campinas: UNICAMP; 2020[cited 2020 Jul 01]. p.109. Available from: https://brazil.unfpa. org/sites/default/files/pub-pdf/miginternacional.pdf

11. Belo E. EUA levam brasileiros mais qualificados. Valor Econômico [Internet]. 2018[cited 2020 Jul 01]. Available from: https:// valor.globo.com/brasil/noticia/2018/05/07/eua-levam-brasileiros-mais-qualificados.ghtml

12. Cortês A, Furtado AB. Como viver em Portugal depois de aposentar. Eurodicas [Internet]. 2019[cited 2020 Jul 01]. Available from: https://www.eurodicas.com.br/como-viver-em-portugal-depois-de-aposentar/ 
13. Campos y Covarrubias G. El fenómeno de la migración México-Estados Unidos desde una perspectiva social. Rev UNAM. 2008[cited 2020 Jul 01];19:9-22. Available from: http://www.revistas.unam.mx/index.php/ents/article/view/20086/19173

14. Figueroa-Hernández E, Pérez-Soto F. El proceso de asentamiento de la migración México-Estados Unidos. Pap Poblac [Internet]. 2008[cited 2020 Jul 01];68:161-90. Available from: http://www.scielo.org.mx/pdf/pp/v17n68/v17n68a8.pdf

15. Hebrero M. Eventos cruciales y ciclos familiares avanzados: el efecto del envejecimiento en los hogares de México. Pap Poblac [Internet]. 2004[cited 2020 Jul 01];12(50). Available from: http://www.scielo.org.mx/pdf/pp/v12n50/v12n50a6.pdf

16. De Haas H. Mobility and human development: Human Development Research Paper [Internet]. 2009[cited 2020 Jul 01]. p. 73. Available from: http://hdr.undp.org/en/content/mobility-and-human-development

17. Organización Internacinonal para La Migración. Informe regional sobre determinantes de salud de las personas migrantes retornadas o em trânsito y sus famílias em centroamérica [Internet]. 2015[cited 2020 Jul 01]. Available from: https:// saludymigracion.org/es/informe-regional-sobre-determinantes-de-la-salud-de-las-personas-migrantes-retornadas-o-en-0

18. Comisión Económica para América Latina y el Caribe (CEPAL). Huenchuan S. COVID-19: recomendaciones generales para la atención a personas mayores desde una perspectiva de derechos humanos [Internet].. 2020[cited 2020 Jul 01];LC/MEX/ TS.2020/6/Rev.1. Available from: https://repositorio.cepal.org/handle/11362/45316. 